\title{
Effects of Experimental Removal of Barred Owls on Population Demography of Northern Spotted Owls in Washington and Oregon—2017 Progress Report
}

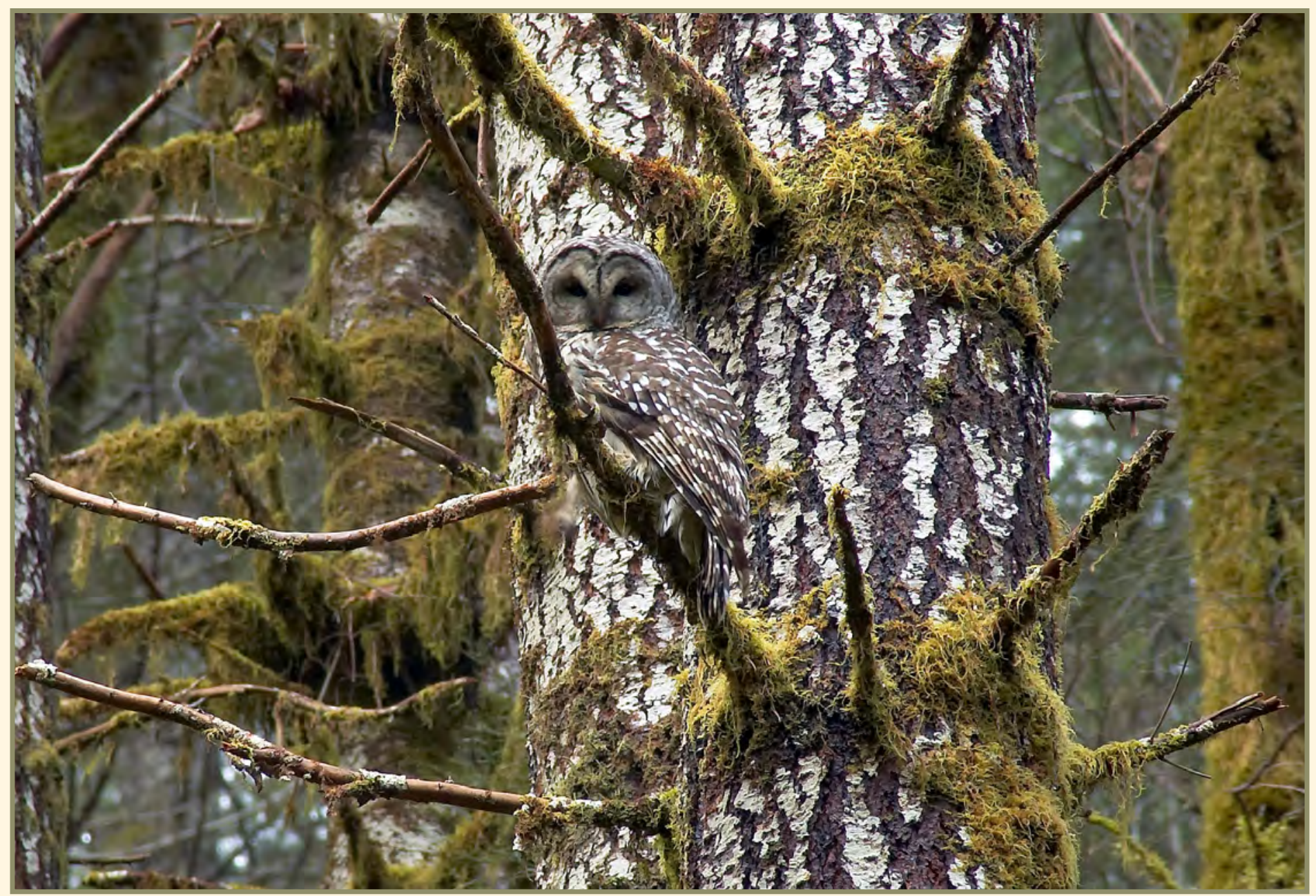

Open-File Report 2018-1086

U.S. Department of the Interior

U.S. Geological Survey 
Cover: Photograph of a female Barred Owl (Strix varia) in the Oregon Coast Range. Photograph copyright by Patrick Kolar, Oregon State University, 2006. Used with permission. 


\section{Effects of Experimental Removal of Barred Owls on Population Demography of Northern Spotted Owls in Washington and Oregon-2017 Progress Report}

By J. David Wiens, Katie M. Dugger, Damon B. Lesmeister, Krista E. Dilione, and David C. Simon

Open-File Report 2018-1086 


\title{
U.S. Department of the Interior \\ RYAN K. ZINKE, Secretary
}

\author{
U.S. Geological Survey \\ James F. Reilly II, Director
}

U.S. Geological Survey, Reston, Virginia: 2018

For more information on the USGS—-the Federal source for science about the Earth, its natural and living resources, natural hazards, and the environment-visit https://www.usgs.gov/ or call 1-888-ASK-USGS (1-888-275-8747).

For an overview of USGS information products, including maps, imagery, and publications, visit https:/store.usgs.gov.

Any use of trade, firm, or product names is for descriptive purposes only and does not imply endorsement by the U.S. Government.

Although this information product, for the most part, is in the public domain, it also may contain copyrighted materials as noted in the text. Permission to reproduce copyrighted items must be secured from the copyright owner.

Suggested citation:

Wiens, J.D., Dugger, K.M., Lesmeister, D.B., Dilione, K.E., and Simon, D.C., 2018, Effects of experimental removal of Barred Owls on population demography of Northern Spotted Owls in Washington and Oregon-2017 progress report: U.S. Geological Survey Open-File Report 2018-1086, 23 p., https://doi.org/10.3133/ofr20181086.

ISSN 2331-1258 (online) 


\section{Contents}

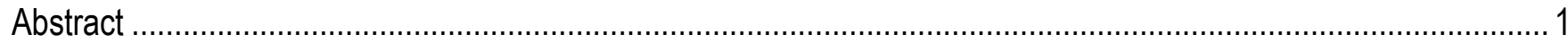

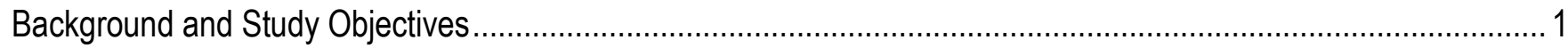

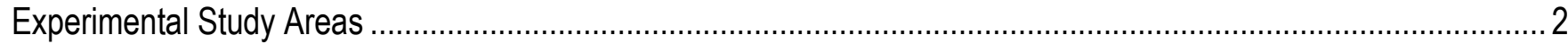

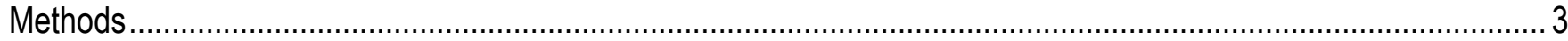

Population Monitoring.....................................................................................................................

Barred Owl Removal and Scientific Collection ......................................................................................

Estimating the Initial Effects of Removals on Barred Owls .........................................................................5

Probability of Use by Territorial Pairs ...............................................................................................

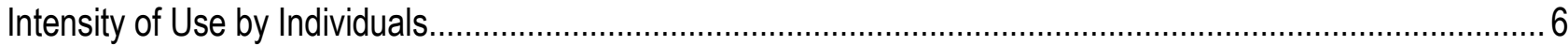

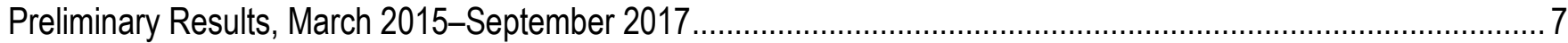

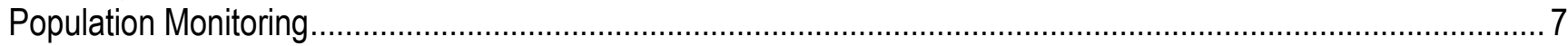

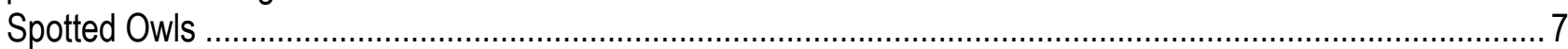

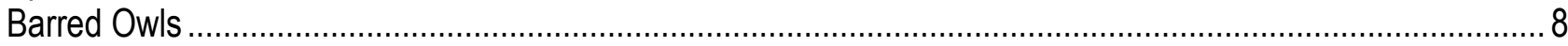

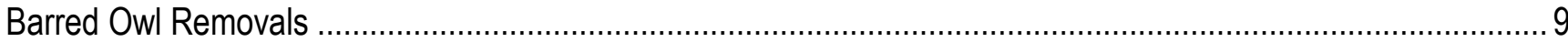

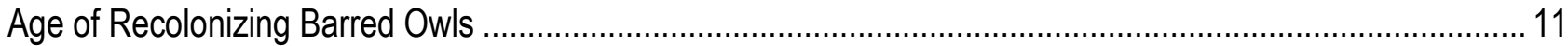

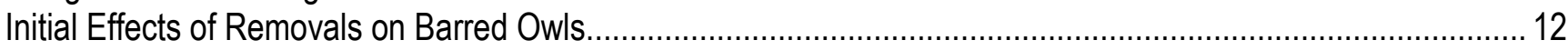

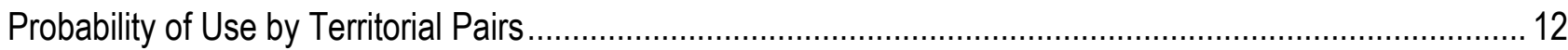

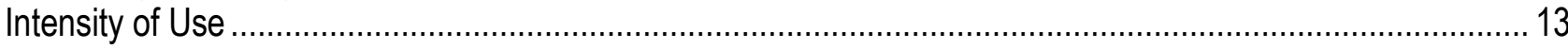

Associated Research Activities and Accomplishments .............................................................................. 15

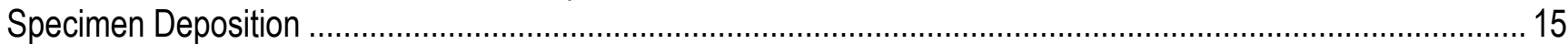

Characterizing the Broader Ecological Impacts of Barred Owls ................................................................. 15

Barred Owls and Rodenticide Exposure in Non-Target Forest Wildlife ........................................................... 15

Simulation Studies of Barred Owl Removal Strategies.............................................................................. 16

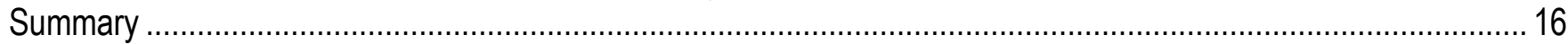

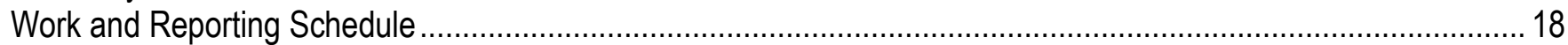

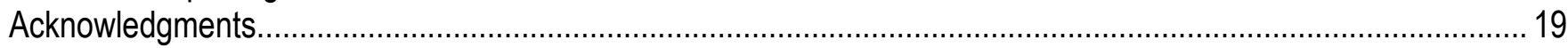

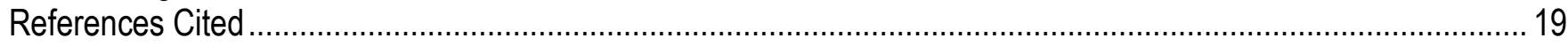

Appendix 1. Ranking of Multi-Season Occupancy Models Used to Characterize Variation in the Probabilities of Use, Extinction, Colonization, and Detection of Territorial Pairs of Barred Owls on Three Experimental Study Areas in Washington and Oregon, 2015-17.

Appendix 2. Ranking of Single-Season $\mathrm{N}$-mixture Models Used to Characterize Variation in Intensity of Use, and Detection of Individual Barred Owls on Three Experimental Study Areas in Washington and Oregon, 2015-17

\section{Figures}

Figure 1. Control (no Barred Owls removed) and treatment (Barred Owls removed) portions of three study areas in Washington and Oregon used to determine the effects of experimental removal of Barred Owls on population demography of northern Spotted Owls

Figure 2. Example of spatial overlap between sites surveyed annually for northern Spotted Owls (historical territories) and Barred Owls (500-hectare hexagons) in the Oregon Coast Range study area..... 
Figure 3. Long-term trend in (A) the proportion of historical territories with detections of resident pairs of northern Spotted Owls and (B) the mean number of young fledged per territorial pair of Spotted Owls on treatment compared with control areas of three study areas in Washington and Oregon, 1990-2017.

Figure 4. Distribution of removal times (cumulative time between arrival at a site and successful collection of a Barred OwI) for 382 female and 449 male Barred Owls lethally removed from treatment areas in Washington and Oregon, 2015-17.

Figure 5. Change in the proportion of Barred Owls collected during experimental removals that were either adults (greater than or equal to 3 years-old) or subadults (1-2 years old) at three study areas in Washington and Oregon, September 2015-August 2017.

Figure 6. Model averaged pre- and post-treatment estimates $( \pm 95$ percent unconditional confidence intervals) of (A) the probability of use by at least 1 territorial pair of Barred Owls $(\psi)$; and (B) intensity of use by individual Barred Owls in treatment and control areas in Washington and Oregon, 2015-17.

\section{Tables}

Table 1. Northern Spotted Owl survey effort, detections of resident pairs at historical nesting territories, and number of pairs that successfully reproduced ( $\geq 1$ young fledged) on treatment (Barred Owls removed) compared with control (Barred Owls not removed) areas in three study areas in Washington and Oregon, 2015-17.

Table 2. Barred Owl survey effort, detections of territorial pairs, and total individuals detected during annual surveys completed on treatment and control areas in three study areas in Washington and Oregon, 2015-17....... 9 Table 3. Number of individual Barred Owls removed from established treatment areas in Washington and Oregon, September 2015-September 2017.

Table 4. Model averaged estimates, with standard errors and lower and upper 95-percent confidence intervals, of local extinction and colonization probabilities of territorial pairs of Barred Owls on treatment (Barred Owls removed) and control (no Barred Owls removed) areas in Washington and Oregon, 2015-17

\section{Conversion Factors}

International System of Units to U.S. customary units

\begin{tabular}{|c|c|c|}
\hline Multiply & By & To obtain \\
\hline \multicolumn{3}{|c|}{ Length } \\
\hline meter (m) & 3.281 & foot $(\mathrm{ft})$ \\
\hline \multicolumn{3}{|c|}{ Area } \\
\hline hectare (ha) & 2.471 & acre \\
\hline square kilometer $\left(\mathrm{km}^{2}\right)$ & 0.3861 & square mile $\left(\mathrm{mi}^{2}\right)$ \\
\hline
\end{tabular}




\title{
Effects of Experimental Removal of Barred Owls on Population Demography of Northern Spotted Owls in Washington and Oregon-2017 Progress Report
}

\author{
By J. David Wiens ${ }^{1}$, Katie M. Dugger², Damon B. Lesmeister ${ }^{3}$, Krista E. Dilione ${ }^{1}$, and David C. Simon ${ }^{1}$
}

\begin{abstract}
Populations of Northern Spotted Owls (Strix occidentalis caurina; hereinafter referred to as Spotted Owl) are declining throughout this subspecies' geographic range. Evidence indicates that competition with invading populations of Barred Owls $(S$. varia) has contributed significantly to those declines. A pilot study in California showed that localized removal of Barred Owls coupled with conservation of suitable forest conditions can slow or even reverse population declines of Spotted Owls. It remains unknown, however, whether similar results can be obtained in areas with different forest conditions, greater densities of Barred Owls, and fewer remaining Spotted Owls. During 2015-17, we initiated a before-after-control-impact (BACI) experiment at three study areas in Oregon and Washington to determine if removal of Barred Owls can improve population trends of Spotted Owls. Each study area had at least 20 years of pre-treatment demographic data on Spotted Owls, and represented different forest conditions occupied by the two owl species in the Pacific Northwest. This report describes research accomplishments and preliminary results from the first 2.5 years (March 2015-August 2017) of the planned 5-year experiment.
\end{abstract}

\section{Background and Study Objectives}

Over the past century, Barred Owls have expanded their geographic range west from eastern North America, and their newly expanded range now completely overlaps that of the federally threatened northern Spotted Owl. Evidence indicates that competition with invading Barred Owls has contributed significantly to declines in populations of Spotted Owls (Wiens and others, 2014; Dugger and others, 2016). A pilot study in coastal California, for example, demonstrated that removal of Barred Owls in combination with conservation of suitable forest conditions can slow or even reverse population declines of Spotted Owls (Diller and others, 2016). It remains unknown, however, whether similar results can be obtained in areas with different forest conditions, greater densities of Barred Owls, and fewer remaining Spotted Owls. Ultimately, the long-term persistence of Spotted Owls may be in question without management intervention to reduce the threat of Barred Owls.

${ }^{1}$ U.S. Geological Survey, Forest and Rangeland Ecosystem Science Center.

${ }^{2}$ U.S. Geological Survey, Oregon Cooperative Fish and Wildlife Research Unit, Oregon State University.

${ }^{3}$ U.S. Forest Service, Pacific Northwest Research Station. 
In 2013, the U.S. Fish and Wildlife Service (USFWS) released a Final Environmental Impact Statement and Record of Decision for the experimental removal of Barred Owls to benefit Spotted Owls (U.S. Fish and Wildlife Service, 2013). After considering a range of approaches, the U.S. Fish and Wildlife Service (2013) identified four study areas with at least 20 years of pre-treatment demographic data on Spotted Owls to do removal experiments. The experiments would provide a definitive test of whether competitive interactions with Barred Owls cause population declines of Spotted Owls, and if so, whether localized removal of Barred Owls is an effective tool to consider in long-term management and conservation of Spotted Owls.

In 2015, we started population surveys and experimental removal of Barred Owls in three study areas in Washington and Oregon (also see Wiens and others, 2017). Experimental removals began at a fourth study area in northwestern California in 2013 (Hoopa/Willow Creek), and preliminary results from that part of the study are summarized in Franklin and others (2016) and Higley (2017). The overall goal of the removal experiment was to test the research hypothesis that competitive interactions with Barred Owls causes declines in the annual rate of population change $\left(\lambda_{t}\right)$ of Spotted Owls, or one of the demographic components governing change in $\lambda_{t}$ (that is, survival, reproduction, or recruitment; also see Johnson and others, 2008). Specific study objectives are to:

1. Determine the effect of experimental removal of Barred Owls on populations of Spotted Owls with respect to site-occupancy dynamics, reproduction, survival, recruitment, and annual rate of population change $\left(\lambda_{t}\right)$;

2. Estimate pre- and post-removal differences in occurrence of Barred Owls in control and treatment parts of each study area; and

3. Characterize the amount of effort and cost required to maintain low numbers of Barred Owls and achieve positive effects on vital rates of territorial Spotted Owls.

Based on previous studies of competitive interactions (Wiens and others, 2014; Diller et al. 2016), we predicted that competitive release from Barred Owls in treatment areas would increase territory occupancy, reproduction, recruitment, and survival (or reduce emigration rates) of Spotted Owls relative to control areas where Barred Owls are not removed.

In this report, we provide an overview of our research accomplishments and initial results from the first 2.5 years (March 2015-August 2017) of implementing removal experiments in Oregon and Washington. We focus on initial results of population monitoring in treatment and control areas, Barred Owl removal efforts, and the effects of initial removal efforts on populations of Barred Owls. We also provide an overview of several new studies associated with experimental removal and scientific collection of Barred Owls. Future reports will address specific study objectives listed above after data collection and demographic analyses are complete (see Work and Reporting Schedule below).

\section{Experimental Study Areas}

We started the study in three long-term demographic study areas for Spotted Owls in Washington and Oregon: Cle Elum, Oregon Coast Range, and Klamath-Union/Myrtle (Klamath-UM; fig. 1). The areas varied in climate, vegetation composition, and topography, but all were dominated by conifer or mixed conifer-hardwood forests (Dugger and others, 2016). These areas initially were selected based on many considerations, including availability of pre-treatment demographic data on Spotted Owls, land ownership, and the need to identify the effect of Barred Owls on Spotted Owls across a range of different forest conditions used by Spotted Owls (U.S. Fish and Wildlife Service, 2013). The study areas are composed of mostly Federal lands, but fieldwork also occurred on adjacent state and private lands with the written permission of the landowner. A mixture of public and private lands was included so that study results would not be limited to certain ownerships. 


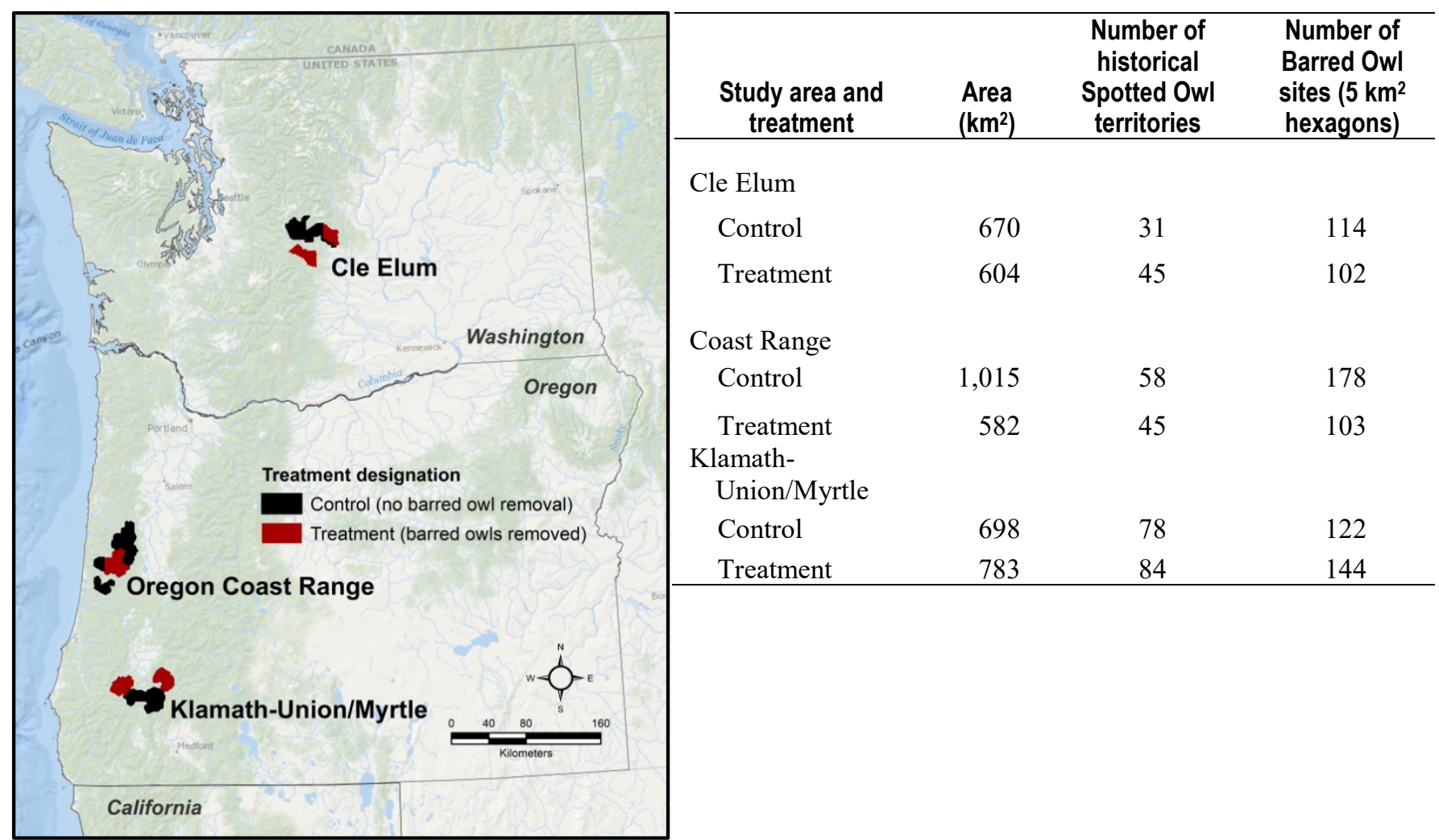

Figure 1. Control (no Barred Owls removed) and treatment (Barred Owls removed) portions of three study areas in Washington and Oregon used to determine the effects of experimental removal of Barred Owls on population demography of northern Spotted Owls.

\section{Methods}

\section{Population Monitoring}

We used species-specific surveys of Spotted Owls and Barred Owls to track annual changes in populations on control and treatment areas (figs. 1 and 2). We surveyed Spotted Owls at historically occupied territories as part of a long-term demographic monitoring program (Lint and others, 1999; Dugger and others, 2016; Lesmeister, Horn, and others, 2018; Lesmeister, McCafferty, and others, 2018; Lesmeister, Sovern, and Mikkelsen, 2018). We used standardized field protocols to determine territory occupancy and reproductive status of individually color-marked Spotted Owls (Franklin and others, 1996). Each year we surveyed Spotted Owls during the breeding season (March-August) to document territory occupancy, locate territorial owls, confirm bands of previously color-marked owls, band previously unmarked owls, and determine the number of young produced by territorial pairs (Lint and others, 1999). We used Theissen polygons to delineate individual nesting territories used by Spotted Owls, based on the cumulative area where a single resident Spotted Owl, or pair of Spotted Owls, was detected during annual surveys (Dugger and others, 2016). We used long-term (1990-2017) monitoring data on Spotted Owls to summarize observed (naïve) estimates of territory occupancy and reproduction (proportion of territorial pairs breeding, number of young fledged) in control and treatment areas. 
Recent summaries of Spotted Owl population trends, territorial owls detected, breeding and mate status of detected owls, number of owls banded, reproduction, inter-territory movements, and general age distribution are described elsewhere (Lesmeister, Horn, and others, 2018; Lesmeister, McCafferty, and others, 2018; Lesmeister, Sovern, and Mikkelsen, 2018).

We used methods described by Wiens and others $(2011 ; 2014)$ to survey Barred Owls and track pre- and post-treatment changes in populations on control and treatment areas. Our sampling scheme for Barred Owls used a standard occupancy design (MacKenzie and others, 2002; 2006) in which a grid of 500-hectare (ha) hexagons were overlaid on each study area (fig. 2) and surveyed repeatedly during three sampling periods each year: March 1-May 7; May 8-July 9; and July 10-September 10. These sampling periods were established to approximate mean transition dates between incubation, nestling, and fledgling-dependency breeding stages of Barred Owls (Wiens and others, 2011; 2014). During each survey, observers used an amplified megaphone (FoxPro, Lewiston, Pennsylvania, and Wildlife Technologies, Manchester, New Hampshire) to broadcast digitally recorded calls of Barred Owls at established call points, distributed to provide complete coverage of the focal survey hexagon. Observers recorded the number and sex of Barred Owls detected during each survey of a focal hexagon. A hexagon was considered used by at least 1 territorial pair of Barred Owls if (1) both sexes were observed within 400 meters $(\mathrm{m})$ of each other on a single visit or (2) at least one adult was observed with young (Wiens and others, 2011).

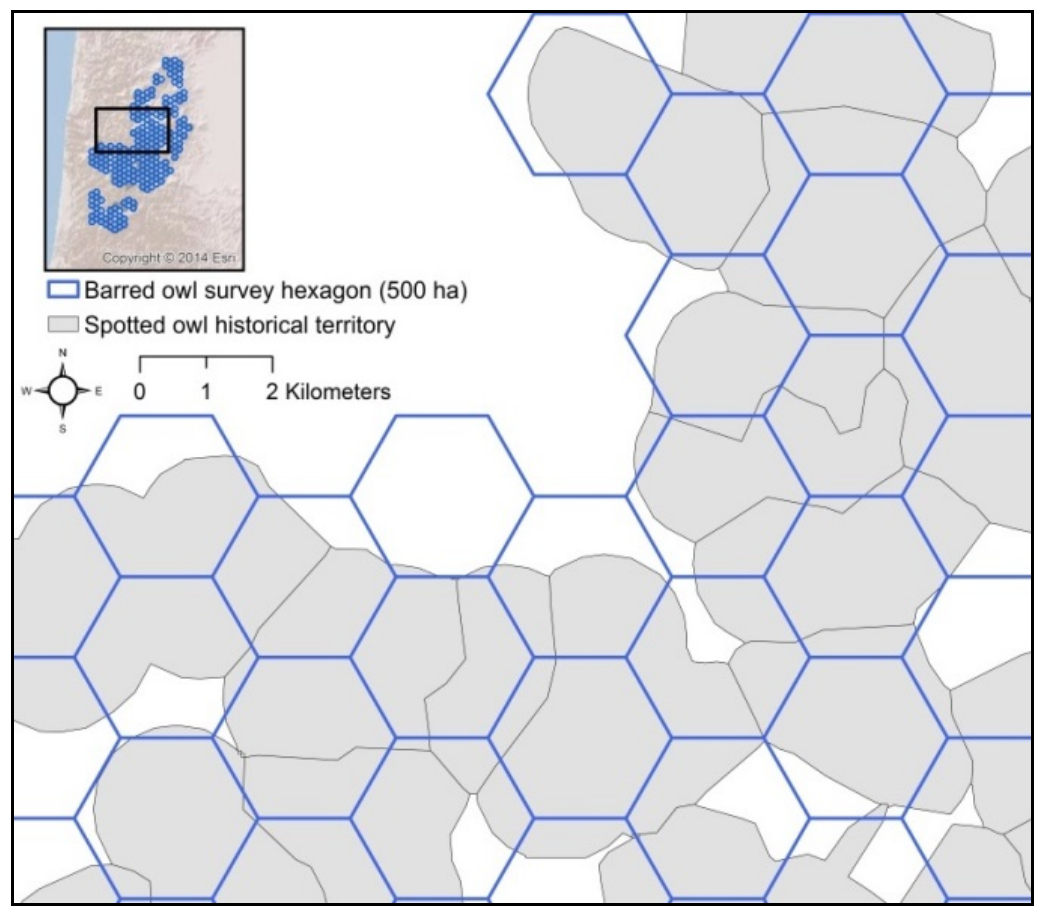

Figure 2. Example of spatial overlap between sites surveyed annually for northern Spotted Owls (historical territories) and Barred Owls (500-hectare hexagons) in the Oregon Coast Range study area. 


\section{Barred Owl Removal and Scientific Collection}

We used well-established field protocols for experimental removal and scientific collection of Barred Owls (U.S. Fish and Wildlife Service, 2013; Diller and others, 2014, 2016). Barred Owls detected in treatment areas during population surveys were subsequently removed using 12-gauge shotguns with non-toxic bird shot (Diller and others, 2014). We anticipated frequent recolonization of Barred Owls into removal areas (Yackulic and others, 2014; Diller and others, 2014, 2016), so we did regular follow-up visits to detect Barred Owls at these sites and make additional removals as needed. Removal of Barred Owls by U.S. Geological Survey (USGS)-certified personnel was authorized under Federal and State permits. The Institutional Animal Care and Use Committee (IACUC) at Oregon State University approved all survey and removal methods used for Barred Owls in this study.

Our protocol for removals prohibited collection of nesting Barred Owls with dependent young (U.S. Fish and Wildlife Service, 2013). Because of difficulties and additional costs in determining nesting status of Barred Owls, removals occurred primarily during the nonbreeding season (approximately September-March). As specified by U.S. Fish and Wildlife Service (2013), however, removal of non-nesting Barred Owls may be permitted during the breeding season in cases where observers have high confidence in determining nesting status of individuals detected. In 2017, we received approval from USFWS to do localized removals of Barred Owls during the breeding season at sites where we observed rapid (2-3 week) recolonization by Barred Owls following removals in early spring (March-April). We reasoned that colonists arriving at sites after the estimated mean hatching

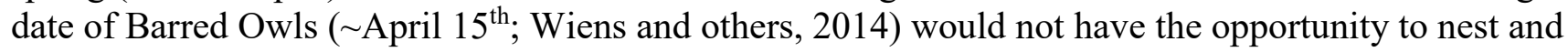
produce young between repeated field-visits. We focused our removal efforts during the breeding season at sites with detections of territorial pairs of Spotted Owls in the previous year. We did not conduct breeding season removals in Cle Elum because snow limited our ability to visit areas frequently enough to be confident that any new Barred Owls detected were not nesting.

We determined sex of Barred Owls based on vocalizations and a standard set of morphometric measurements used for birds of prey (Wiens and others, 2014). All Barred Owls that were lethally removed and successfully collected were classified as either adults ( $\geq 3$ years old) or subadults (1-2 years old) based on molt and plumage characteristics observed under ultraviolet light (Weidensaul and others, 2011). All measurements were taken at the time of collection. In a preliminary assessment of removal effort, we calculated the mean number of minutes between the arrival time at a removal site and the collection time of an individual owl. We calculated removal times for sexes separately because Diller and others (2014) determined that males took more effort to remove than females.

\section{Estimating the Initial Effects of Removals on Barred Owls}

We used two measures to quantify and track the effects of experimental removals on populations of Barred Owls over time: (1) probability of use by territorial pairs (based detection/non-detection of pairs during breeding season surveys); and (2) intensity of use of survey sites (based on counts of individual Barred Owls detected during surveys).

\section{Probability of Use by Territorial Pairs}

We used multi-season dynamic occupancy models in program MARK (White and Burnham, 1999) to evaluate how removals influenced probability of use by territorial pairs of Barred Owls. This approach permitted us to estimate the effects of removals on extinction (or mortality) and colonization 
processes of Barred Owls in control and treatment sites. A sample site in our study was a 500-ha hexagon used to survey Barred Owls. For this analysis, we focused inferences on detections/nondetections of $\geq 1$ pair of Barred Owls. We did this because pairs have the potential to reproduce, and thus have greater effects on the local population of Spotted Owls (and recolonization of removal sites). Actual territory boundaries of Barred Owls may overlap more than 1 survey site in our study, so we interpreted the occupancy parameter $(\psi)$ as the probability of $\geq 1$ territorial pair of Barred Owls using a site during the breeding season (MacKenzie and others, 2002; 2006). We used detection histories from breeding season surveys to estimate: the pre-treatment probability of use by $\geq 1$ pair of Barred Owls in the first year of the study $\left(\psi_{1}\right)$; the probability that a previously used site was not used in the subsequent year (local extinction, $\varepsilon$ ); the probability that a vacant site was used in the subsequent year (local colonization, $\gamma$ ); and the probability of detection $(p)$. At sites where we did year-round removals in 2017 $(n=39)$, we considered only surveys within a breeding season that occurred prior to removal of the last Barred Owl at a site to avoid biasing parameter estimates (Diller and others, 2016).

\section{Intensity of Use by Individuals}

We used $N$-mixture models (Royle, 2004) to estimate intensity of use of treatment and control areas by Barred Owls. This approach used spatially replicated counts of individuals detected during surveys, instead of detection/nondetection data on territorial pairs. The $N$-mixture model typically is used to estimate density ( $\lambda$, the mean number of individuals per sample site), which assumes that (1) there is within-plot closure during the primary sampling period and (2) detection histories among sample sites are independent. Our study design minimized the likelihood of violating of these assumptions, but we could not rule out this possibility because sites were not centered on actual territory locations and individuals were not marked. Consequently, estimates of $\lambda$ are likely to overestimate actual density of Barred Owls. Rather, we interpret $\lambda$ as intensity of use (that is, the average number of individuals whose home ranges overlap with the focal survey site [Nichols and others, 2009; Barker and others, 2017]). We used program MARK to estimate $\lambda$ and the associated detection parameter, $r$ (Royle, 2004). We did not simulate the effect of survey occasion on $r$ because the $N$-mixture model assumes constant within-season detectability. Models including study area effects on $r$ produced unstable estimates for some areas, so we assumed similar detection rates among study areas for this analysis.

We used a two-stage approach to examine evidence for treatment (removal) and time (year) effects on occupancy parameters of Barred Owls. At each stage, we used information theoretic methods to rank and select the best model (Burnham and Anderson, 2002). First, we identified the best model for detection. At this stage, alternative models were considered with and without treatment and time effects, including a model with a year-specific variable (trtBA) that permitted estimates of detection to vary between control and treatment sites, but only after removals. Next, we retained the best-supported model of detection and continued to model occupancy parameters with and without treatment and time effects. In the dynamic analysis of probability of use $(\psi)$, we considered 12 alternative models in which colonization and extinction parameters were constant between treatment and control sites and among years, varying with treatment but constant over years, or varying with treatment and years. Study areas were analyzed separately to accommodate differences in the number of years of data for each area. For $N$-mixture modeling, study areas were analyzed jointly and a set of 14 alternative models was ranked with and without the effects of study area, year, and treatment on estimates of $\lambda$ and $r$. We evaluated the degree to which 95 percent confidence intervals of regression coefficients $(\beta)$ overlapped zero to determine the strength of treatment effects. We calculated model-averaged estimates where appropriate. 


\section{Preliminary Results, March 2015-September 2017}

\section{Population Monitoring}

\section{Spotted Owls}

Field crews completed annual surveys of Spotted Owls at 341 historical territories located in control and treatment portions of three study areas in Washington and Oregon (table 1). ${ }^{4}$ The proportion of historical territories where we detected resident pairs of Spotted Owls ranged from 4 percent in Cle Elum to 15 percent in Klamath-UM (table 1). Few pairs successfully fledged young in 2017 (table 1). Observed estimates of territory occupancy and reproduction of Spotted Owls illustrated little response to the first 1-2 seasons of experimental removals of Barred Owls (table 1, fig. 3).

Table 1. Northern Spotted Owl survey effort, detections of resident pairs at historical nesting territories, and number of pairs that successfully reproduced ( $\geq 1$ young fledged) on treatment (Barred Owls removed) compared with control (Barred Owls not removed) areas in three study areas in Washington and Oregon, 2015-17.

[Parentheses show the proportion (percentage) of historical territories surveyed with detections of pairs and the proportion of pairs detected with successful reproduction. Shading indicates post-treatment estimates.]

\begin{tabular}{|c|c|c|c|c|c|c|c|}
\hline \multirow{2}{*}{$\begin{array}{c}\text { Study area } \\
\text { and treatment }\end{array}$} & \multirow{2}{*}{$\begin{array}{l}\text { Historical } \\
\text { territories } \\
\text { surveyed }\end{array}$} & \multicolumn{3}{|c|}{$\begin{array}{l}\text { Historical territories with } \\
\text { pairs of Spotted Owls detected }\end{array}$} & \multicolumn{3}{|c|}{$\begin{array}{c}\text { Territorial pairs with } \\
\text { successful reproduction }\end{array}$} \\
\hline & & 2015 & 2016 & 2017 & 2015 & 2016 & 2017 \\
\hline \multicolumn{8}{|c|}{ Cle Elum, Washington } \\
\hline Control & 31 & $5(0.16)$ & $2(0.06)$ & $2(0.06)$ & $2(0.06)$ & $0(0.00)$ & $2(0.06)$ \\
\hline Treatment & 45 & $2(0.04)$ & $2(0.04)$ & $2(0.04)$ & $1(0.02)$ & $2(0.04)$ & $1(0.02)$ \\
\hline \multicolumn{8}{|c|}{ Coast Range, Oregon } \\
\hline Control & 58 & $11(0.19)$ & $9(0.16)$ & $6(0.10)$ & $3(0.05)$ & $0(0.00)$ & $1(0.02)$ \\
\hline Treatment & 45 & $3(0.07)$ & $5(0.11)$ & $4(0.09)$ & $0(0.00)$ & $1(0.02)$ & $2(0.04)$ \\
\hline \multicolumn{8}{|c|}{ Klamath-UM, Oregon } \\
\hline Control & 78 & $18(0.23)$ & $14(0.18)$ & $11(0.14)$ & $8(0.10)$ & $1(0.01)$ & $3(0.04)$ \\
\hline Treatment & 84 & $23(0.27)$ & $12(0.14)$ & $13(0.15)$ & $6(0.07)$ & $1(0.01)$ & $2(0.02)$ \\
\hline
\end{tabular}

${ }^{4}$ Data reported on site occupancy and reproduction of Spotted Owls are specific to the experimental (control/treatment) portions of each study area, so may vary from those reported in these areas by the Northern Spotted Owl Northwest Forest Plan Monitoring Program (see:

www.fs.fed.us/r6/reo/monitoring/reports/). 

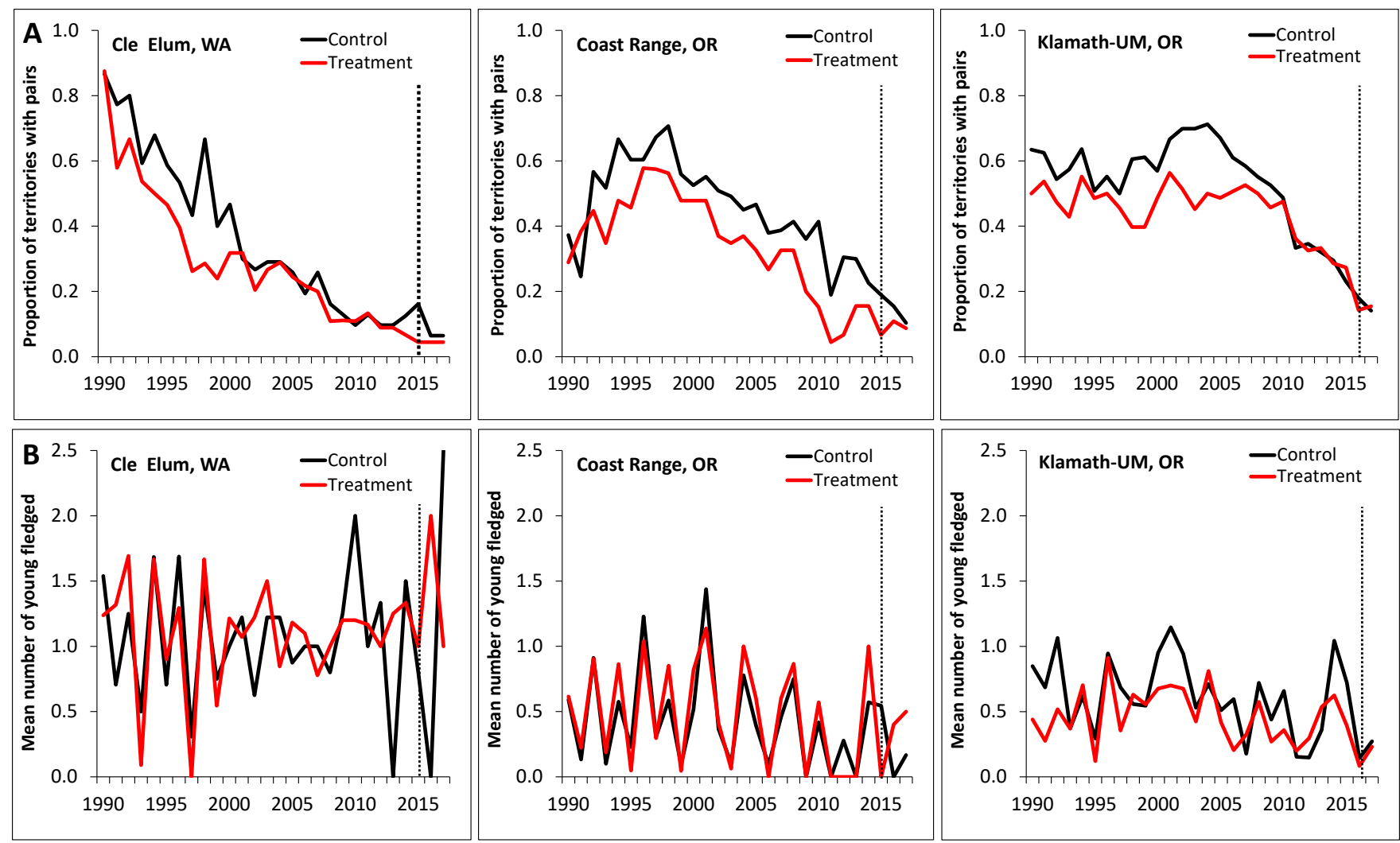

Figure 3. Long-term trend in (A) the proportion of historical territories with detections of resident pairs of northern Spotted Owls and (B) the mean number of young fledged per territorial pair of Spotted Owls on treatment compared with control areas of three study areas in Washington and Oregon, 1990-2017. Dashed vertical lines indicate the year in which experimental removal of Barred Owls was implemented in treatment areas.

\section{Barred Owls}

We completed annual surveys of Barred Owls at 762 survey sites (500-ha hexagons) in control and treatment (removal) areas in Washington and Oregon (table 2). Surveys and removals of Barred Owls were started in the Cle Elum and Oregon Coast Range study areas in 2015, but not until 2016 in Klamath-UM because of delays in securing access agreements with private landowners. During 201517, the proportion of sites surveyed with detections of territorial pairs of Barred Owls declined by 22 percent and 44 percent in the Oregon Coast Range and Cle Elum treatment areas, respectively. We also observed before-after/control-treatment differences in the total number of individuals detected (sum of maximum counts per site) and mean number of Barred Owls detected per survey (table 2). In contrast, the proportion of sites with pairs of Barred Owls, and the mean number of individual Barred Owls detected, remained relatively constant (or increasing) in control areas. In Klamath-UM, the proportion of sites with pairs of Barred Owls detected declined by 4 percent in treatment areas after one season of removals, but increased by 18 percent in the control area. We detected 2.6-3.3 times as many Barred Owls in the Oregon Coast Range as compared to the Klamath-UM and Cle Elum study areas. 
Table 2. Barred Owl survey effort, detections of territorial pairs, and total individuals detected during annual surveys completed on treatment and control areas in three study areas in Washington and Oregon, 2015-17.

[Total number of individuals detected was the annual sum of maximum counts per 500-ha survey plot. Parentheses show the proportion (percentage) of Barred Owls detected or mean number of individuals per site. Shading indicates post-treatment estimates. ha, hectare]

\begin{tabular}{|c|c|c|c|c|c|c|c|}
\hline \multirow{2}{*}{$\begin{array}{l}\text { Study area and } \\
\text { treatment }\end{array}$} & \multirow{2}{*}{$\begin{array}{c}\text { Sites } \\
(500-h a \\
\text { hexagons) } \\
\text { surveyed }\end{array}$} & \multicolumn{3}{|c|}{$\begin{array}{l}\text { Sites with } \geq 1 \text { pairs of } \\
\text { Barred Owls detected }\end{array}$} & \multicolumn{3}{|c|}{$\begin{array}{l}\text { Total number of individual } \\
\text { Barred Owls detected }\end{array}$} \\
\hline & & 2015 & 2016 & 2017 & 2015 & 2016 & 2017 \\
\hline \multicolumn{8}{|c|}{ Cle Elum, Washington } \\
\hline Control & 114 & $61(0.54)$ & $49(0.43)$ & $51(0.45)$ & $182(1.6)$ & $182(1.6)$ & $176(1.5)$ \\
\hline Treatment & 102 & $66(0.65)$ & $31(0.30)$ & $21(0.21)$ & $226(2.2)$ & $135(1.3)$ & $95(0.9)$ \\
\hline \multicolumn{8}{|c|}{ Coast Range, Oregon } \\
\hline Control & 178 & $120(0.67)$ & $135(0.76)$ & $147(0.83)$ & $456(2.6)$ & $563(3.1)$ & $575(3.2)$ \\
\hline Treatment & 103 & $80(0.78)$ & $69(0.67)$ & $58(0.56)$ & $334(3.2)$ & $303(2.9)$ & $237(2.3)$ \\
\hline \multicolumn{8}{|c|}{ Klamath-UM, Oregon } \\
\hline Control & 122 & & $48(0.39)$ & $66(0.54)$ & & $149(1.2)$ & $221(1.8)$ \\
\hline Treatment & 143 & & $67(0.47)$ & $63(0.44)$ & & $234(1.6)$ & $218(1.5)$ \\
\hline
\end{tabular}

\section{Barred Owl Removals}

From September 21, 2015, to August 1, 2017, we removed 883 Barred Owls from treatment areas, including 382 females, 449 males, and 52 owls of undetermined sex (table 3). We removed a minimum of 194 territorial pairs of Barred Owls, but this did not include cases where we removed a male and female from the same location on separate field visits. We used lethal removal methods for all Barred Owls, except for one adult male captured in the Oregon Coast Range, which was placed at a raptor display in the High Desert Museum in Bend, Oregon. The mean total number of individual Barred Owls removed per site (500-ha hexagon) during the study was $2.0(\mathrm{SD}=2.2)$ in Cle Elum (range $=0-9$ owls), $4.8(\mathrm{SD}=4.2)$ in the Oregon Coast Range (range $=0-25$ owls), and 1.3 $(\mathrm{SD}=1.9)$ in Klamath-UM (range $=0-11$ owls). We removed 50 non-nesting Barred Owls during the 2017 breeding season at a subset of 39 treatment sites (28 sites in Coast Range, 11 sites in Klamath-UM). 
Table 3. Number of individual Barred Owls removed from established treatment areas in Washington and Oregon, September 2015-September 2017.

[Removals were started in Klamath-UM in 2016, and no breeding season removals were done in Cle Elum in 2017. Localized removals were done in the two Oregon areas during the 2017 breeding season at a subset of sites with evidence that newly colonizing Barred Owls did not have dependent young. F, female; M, male; Unk, unknown]

\begin{tabular}{|c|c|c|c|c|c|c|c|c|c|}
\hline \multirow[b]{2}{*}{ Study area } & \multicolumn{3}{|c|}{$\begin{array}{c}2015-16 \\
\text { (Nonbreeding; } \\
\text { September-April) }\end{array}$} & \multicolumn{3}{|c|}{$\begin{array}{c}2016-17 \\
\text { (Nonbreeding; } \\
\text { September-April) }\end{array}$} & \multicolumn{2}{|c|}{$\begin{array}{c}2017 \\
\text { (Breeding; } \\
\text { May-August) }\end{array}$} & \multirow{2}{*}{$\begin{array}{l}\text { Study } \\
\text { total }\end{array}$} \\
\hline & $\mathbf{F}$ & M & Unk & $\mathbf{F}$ & M & Unk & $F$ & M & \\
\hline $\begin{array}{l}\text { Cle Elum, } \\
\text { Washington }\end{array}$ & 55 & 65 & 5 & 30 & 50 & 4 & & & 209 \\
\hline $\begin{array}{l}\text { Coast Range, } \\
\text { Oregon }\end{array}$ & 103 & 122 & 20 & 93 & 105 & 13 & 14 & 20 & 490 \\
\hline $\begin{array}{l}\text { Klamath-UM, } \\
\text { Oregon }\end{array}$ & & & & 80 & 78 & 10 & 7 & 9 & 184 \\
\hline Totals & 158 & 187 & 25 & 203 & 233 & 27 & 21 & 29 & 883 \\
\hline
\end{tabular}

Field crews fired 906 shots from 12-gauge shotguns to lethally remove Barred Owls from treatment areas (first-shot success rate $=97.4$ percent). There were 24 ( 2.7 percent) cases where the first shot was apparently not lethal so a second shot was immediately taken. Thirty-two (3.6 percent) of Barred Owls required euthanasia to ensure rapid death following a single, apparently non-lethal shot. We administered euthanasia immediately following a non-lethal shot using an IACUC-approved Ballista penetrating bolt device (Bunny Rancher, Frankfort, Maine). We successfully recovered 872 carcasses of Barred Owls, but were not able to recover 10 carcasses that stuck high in a tree. At least one Spotted Owl was detected on 63 (4.0 percent) of 1,569 field visits to remove Barred Owls. In cases where both species were detected, removals were done only if the Spotted Owl was vocalizing greater than $150 \mathrm{~m}$ in the opposite direction of the removal location, or if a second observer was present to assist with removals. We had no known cases where a non-target species was mistakenly killed or injured.

On average, field crews successful removed 0.56 Barred Owls per field visit (range $=0-5$ owls; $n=1,569$ field visits). The mean time from arrival at a site to successfully collecting an individual Barred Owl was $42.5(\mathrm{SE}=1.8)$ and $39.9(\mathrm{SE}=1.7)$ minutes for females and males, respectively. In comparison, Diller and others (2014) reported that collection times were significantly greater for males because males tended to reduce calling or aggression if their mate was collected first. Based on this finding, our strategy was to collect the male first when a pair was found, which we believe reduced the amount of time required to collect males in our study. Most ( 81 percent) Barred Owls were collected within 60 minutes after arriving at a site to do removals (fig. 4). 


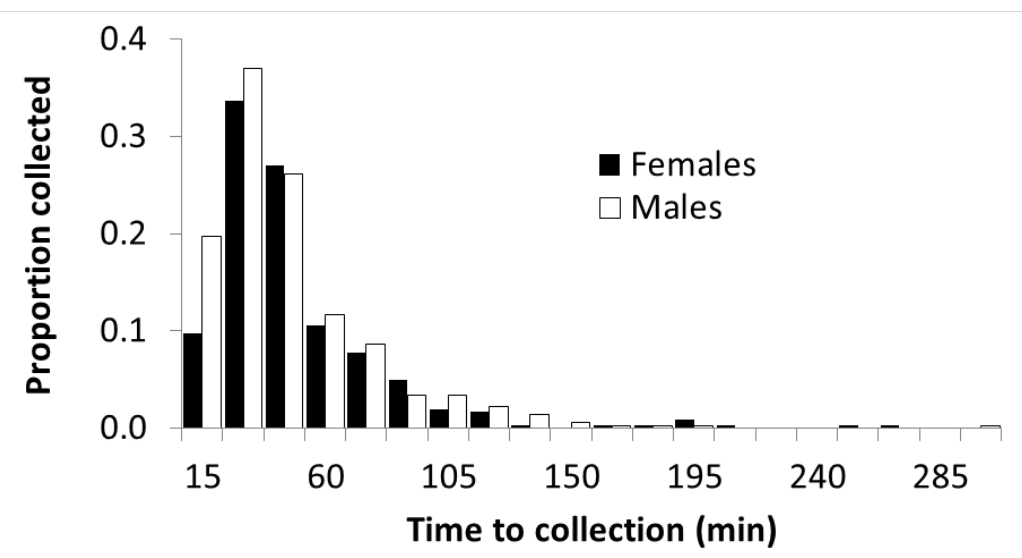

Figure 4. Distribution of removal times (cumulative time between arrival at a site and successful collection of a Barred Owl) for 382 female and 449 male Barred Owls lethally removed from treatment areas in Washington and Oregon, 2015-17.

\section{Age of Recolonizing Barred Owls}

We classified 348 (39 percent) Barred Owls collected during removals as subadults (owls less than 3 years old). We observed a marked increase over time in the proportion of subadult Barred Owls collected, with a concurrent decrease in numbers of adults (fig. 5). This pattern would be expected if younger, first- and second-year owls were available from surrounding landscapes to quickly fill territory vacancies created by removing established territorial birds from treated areas. This finding demonstrated that establishment of breeding territories by subadults increases as numbers of territorial adults are reduced, which supports the hypothesis that age at first breeding can be an indicator of localized increases in mortality of territorial adults (Ferrer and others 2003, Penteriani and others 2011).
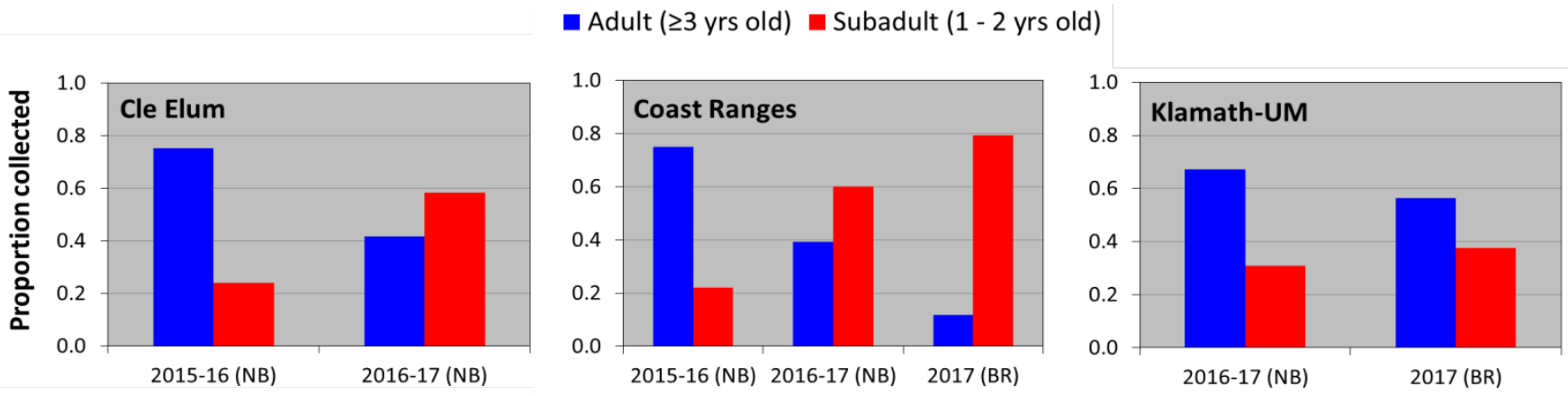

Year and season

Figure 5. Change in the proportion of Barred Owls collected during experimental removals that were either adults (greater than or equal to 3 years-old) or subadults (1-2 years old) at three study areas in Washington and Oregon, September 2015-August 2017. Removals were started at Klamath-UM during the 2016-17 non-breeding season (NB); breeding season removals (BR) were not completed in Cle Elum in 2017. 


\section{Initial Effects of Removals on Barred Owls}

\section{Probability of Use by Territorial Pairs}

According to the best models $\left(\triangle \mathrm{AIC}_{c} \leq 2.0\right)$, there was little evidence for pre-treatment differences in the probability of use by territorial pairs between treatment and control areas (fig. 6A, appendix 1). After removals, model averaged estimates of the probability of use by territorial pairs decreased in treatment areas, but remained relatively constant (or increasing) in control areas. Differences in use between treated and untreated areas became more pronounced after two seasons of removals (fig. 6A) - a pattern similar to that observed in the Diller and others (2016) study. In Cle Elum, estimates of the probability of use in treatment sites declined by 52 percent between 2015 and 2017, and were 22 percent lower relative to control sites after two seasons of removals. During this time, a 16 percent decrease in the probability of use was observed in the Cle Elum control area. In the Oregon Coast Range, the probability of use in treatment sites declined by 24 percent between 2015 and 2017, and was 25 percent lower relative to control sites after two seasons of removals. In Klamath-UM, we observed little change in the probability of use in treatment areas after one season of removals, but observed a concurrent 19 percent increase on control areas (fig. 6A). Estimated detection probabilities for pairs of Barred Owls $(\hat{p})$ ranged from $0.25(\mathrm{SE}=0.06)$ in Cle Elum to $0.74(\mathrm{SE}=0.03)$ in the Oregon Coast Range. Detection was similar between treated and untreated areas prior to removals, but declined by $15-25$ percent in the Cle Elum and Oregon Coast Range treatment areas (but not KlamathUM) after removals (appendix 1).

Local extinction rates were considerably greater in treated areas relative to untreated areas (table 4). Candidate models that included a treatment effect on extinction probability consistently outperformed models without treatment effects, and 95 percent confidence intervals of beta coefficients from top models did not overlap zero for Cle Elum $\left(\hat{\beta}_{\text {trt }}=1.44,95 \% \mathrm{CI}=0.67\right.$ to 2.20$)$ and the Oregon Coast Range $\left(\hat{\beta}_{\text {trt }}=2.21,95 \% \mathrm{CI}=0.76\right.$ to 3.66$)$. Top-models for Klamath-UM that included treatment effects on local extinction indicated positive, albeit imprecise, effects of removals after one season $\left(\hat{\beta}_{\text {trt }}\right.$ $=3.11,95 \% \mathrm{CI}=-20.50$ to 26.71 ; appendix 1). After removals, the probabilities of a site being recolonized by a territorial pair of Barred Owls were substantially greater in the Oregon study areas $(0.38-0.39)$ relative to Cle Elum, Washington (0.11; table 4). Our initial data and results indicated that experimental removals had substantially stronger impacts on local extinction rates of Barred Owls relative to colonization (appendix 1). 
Table 4. Model averaged estimates, with standard errors and lower and upper 95-percent confidence intervals, of local extinction and colonization probabilities of territorial pairs of Barred Owls on treatment (Barred Owls removed) and control (no Barred Owls removed) areas in Washington and Oregon, 2015-17.

[Parameter: $\hat{\boldsymbol{\varepsilon}}$, local extinction; $\widehat{\bar{\gamma}}$, probability of territorial pair SE: standard errors. LCI: lower confidence interval. UCI: upper confidence interval]

\begin{tabular}{|c|c|c|c|c|c|c|c|c|c|}
\hline \multirow[b]{2}{*}{ Parameter } & \multirow{2}{*}{$\begin{array}{c}\text { Study area and } \\
\text { treatment }\end{array}$} & \multicolumn{4}{|c|}{ 2015-16 } & \multicolumn{4}{|c|}{ 2016-17 } \\
\hline & & Estimate & SE & $\mathrm{LCl}$ & $\mathrm{UCl}$ & Estimate & SE & $\mathrm{LCl}$ & $\mathrm{UCl}$ \\
\hline \multirow[t]{9}{*}{ Extinction $(\hat{\overline{\boldsymbol{\varepsilon}}})$} & Cle Elum, Washington & & & & & & & & \\
\hline & Control & 0.194 & 0.045 & 0.120 & 0.298 & 0.194 & 0.045 & 0.120 & 0.298 \\
\hline & Treatment & 0.515 & 0.076 & 0.369 & 0.659 & 0.515 & 0.076 & 0.369 & 0.659 \\
\hline & Coast Range, Oregon & & & & & & & & \\
\hline & Control & 0.009 & 0.010 & 0.001 & 0.029 & 0.043 & 0.030 & 0.010 & 0.157 \\
\hline & Treatment & 0.085 & 0.067 & 0.017 & 0.335 & 0.281 & 0.072 & 0.163 & 0.439 \\
\hline & Klamath-UM, Oregon & & & & & & & & \\
\hline & Control & & & & & 0.070 & 0.107 & 0.003 & 0.650 \\
\hline & Treatment & & & & & 0.159 & 0.110 & 0.036 & 0.487 \\
\hline \multirow[t]{9}{*}{ Colonization $(\hat{\bar{\gamma}})$} & Cle Elum, Washington & & & & & & & & \\
\hline & Control & 0.086 & 0.064 & 0.019 & 0.316 & 0.092 & 0.048 & 0.032 & 0.238 \\
\hline & Treatment & 0.113 & 0.086 & 0.023 & 0.408 & 0.114 & 0.055 & 0.042 & 0.274 \\
\hline & Coast Range, Oregon & & & & & & & & \\
\hline & Control & 0.323 & 0.232 & 0.056 & 0.793 & 0.389 & 0.155 & 0.151 & 0.695 \\
\hline & Treatment & 0.303 & 0.258 & 0.038 & 0.827 & 0.375 & 0.160 & 0.136 & 0.695 \\
\hline & Klamath-UM, Oregon & & & & & & & & \\
\hline & Control & & & & & 0.558 & 0.133 & 0.305 & 0.784 \\
\hline & Treatment & & & & & 0.388 & 0.135 & 0.172 & 0.660 \\
\hline
\end{tabular}

Intensity of Use

Modeling results provided evidence for before-after/control-treatment differences in intensity of use by Barred Owls $(\lambda)$ in the Cle Elum and the Oregon Coast Range areas after two seasons of removals (fig. 6B; appendix 2). Post-treatment differences in Klamath-UM were less pronounced after one season of removals. Model-averaged estimates of intensity of use in treatment areas prior to removals ranged from $3.4(95 \% \mathrm{CI}=2.6-4.1)$ Barred Owls per 500-ha in Klamath-UM to $8.0(95 \% \mathrm{CI}$ $=6.7-9.3$ ) Barred Owls in the Oregon Coast Range (fig. 6B). After removals, intensity of use decreased in treatment areas, but the timing of decrease relative to when removals were started varied among study areas. We observed a steady decline over time in intensity of use by individual Barred Owls in the Cle Elum study area (figs. 6A and B). The best-supported $N$-mixture model of detection probabilities of individuals $(\hat{r})$ indicated that: $(1)$ in treated sites, detection declined from $0.32(95 \% \mathrm{CI}$ $=0.30-0.34)$ prior to removals to $0.24(95 \% \mathrm{CI}=0.21-0.26)$ after removals; and (2) in control sites, detection remained relatively constant over time at $0.33(95 \% \mathrm{CI}=0.32$ to 0.34$)$. 
Treatment (pre-removals)

- Treatment (post-removals)

A OControl (barred owls not removed)
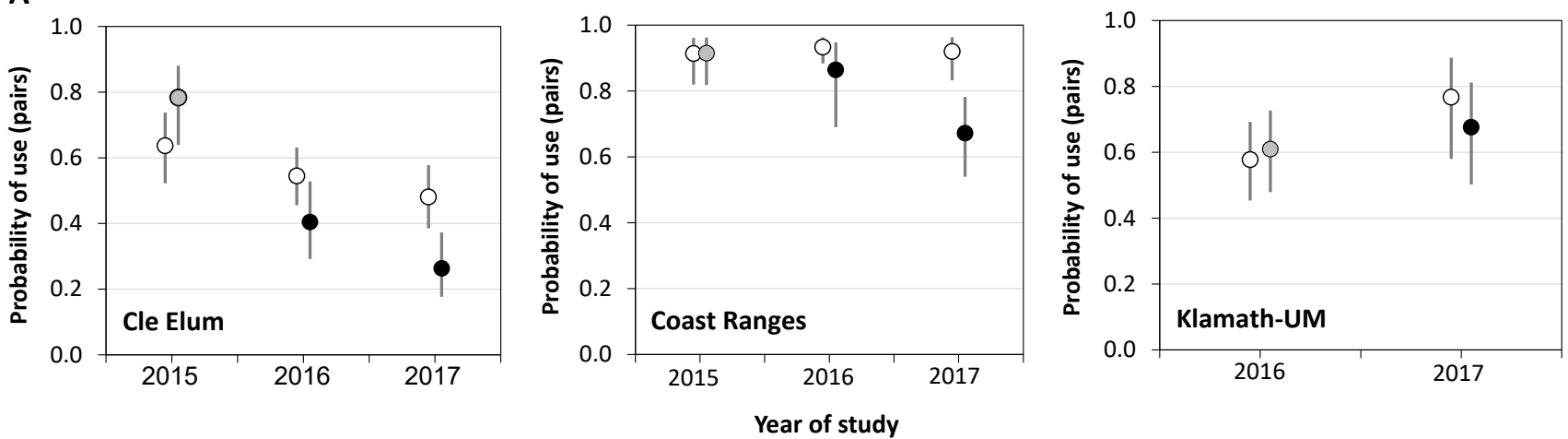

B
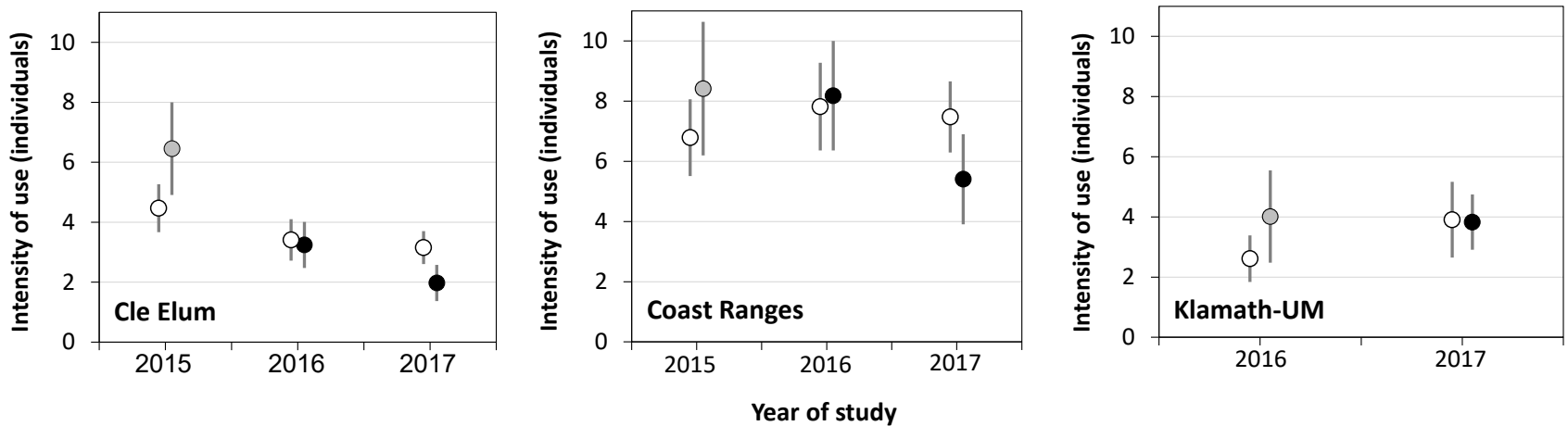

Figure 6. Model averaged pre- and post-treatment estimates ( \pm 95 percent unconditional confidence intervals) of (A) the probability of use by at least 1 territorial pair of Barred Owls $(\widehat{\psi})$; and $(B)$ intensity of use by individual Barred Owls $(\hat{\lambda}$, the mean number of individuals using each 500-ha survey plot) in treatment (Barred Owls removed) and control (no Barred Owls removed) areas in Washington and Oregon, 2015-17. 


\section{Associated Research Activities and Accomplishments}

\section{Specimen Deposition}

Carcasses of Barred Owls are collected and stored locally until they are distributed as scientific specimens to various permitted museums and universities for future research opportunities. As of September 2018, we have provided 406 Barred Owl specimens to 11 research and educational facilities.

\section{Destination}

The Field Museum - Chicago, Illinois

UC Berkeley - Berkeley, California

Burke Museum - Seattle, Washington

California Academy of Sciences - San Francisco, California

Fingerlakes Community College - Canandaigua, New York

The Smithsonian Institution - Washington D.C.

University of Wyoming Museum of Vertebrates, Wyoming

Oregon State University - Corvallis, Oregon

Liberty Wildlife Non-Eagle Feather Repository, Arizona

USGS - FRESC Snake River FS - Boise, Idaho

Oregon Department of Forestry - Tillamook, Oregon

High Desert Museum - Bend, Oregon

Total Barred Owls provided
Purpose

Museum specimen

Museum specimen

Museum specimen $\quad 30$

Museum specimen $\quad 20$

Classroom education $\quad 19$

Museum specimen $\quad 17$

Museum specimen $\quad 15$

Classroom education $\quad 14$

Native American Repository $\quad 10$

Stable isotope analysis; decoy 3

Taxidermy display

Live capture - educational display

\section{Characterizing the Broader Ecological Impacts of Barred Owls}

Rapid increases in the distribution and abundance of an apex predator like the Barred Owl can have cascading effects on native prey species or other competing native predators (Holm and others, 2016). The Barred Owl removal experiment provides a unique opportunity to determine the influence of Barred Owls on other sensitive species, and to test hypotheses broadly relevant to community ecology and the role of top-down predation on structuring biodiversity and ecosystem processes. This study will investigate diets of Barred Owls, foraging ecology, and the broader ecological impact Barred Owls at high densities may be having on the food web of west-coast forests. A Ph.D. candidate at the Department of Fisheries and Wildlife at Oregon State University is currently examining the potential broader ecological impacts of Barred Owls as part of his dissertation research. One component of this research will use stomach contents of Barred Owls collected in the removal experiment to determine diets and identify native prey species that may be negatively affected by high predation rates from Barred Owls. Another component will implement mark-recapture studies of small mammals in experimental study areas to determine how the distribution and abundance of small mammals may be affected by Barred Owls.

\section{Barred Owls and Rodenticide Exposure in Non-Target Forest Wildlife}

The negative effects of anticoagulant rodenticides (ARs) on non-target wildlife have been identified as a potentially serious threat to Spotted Owls and associated forest wildlife (Gabriel and others, 2018). Barred Owls have been shown to provide a useful surrogate for detecting exposure rates of ARs in Spotted Owls and other sensitive native species. In this study, liver samples from Barred Owls specimens will be analyzed and screened for several different types of ARs. This information will be used to characterize and map the frequency and spatial extent of potential AR contamination and exposure rates in the Oregon and Washington study areas. 


\section{Simulation Studies of Barred Owl Removal Strategies}

Our survey data and findings on regional variation in occurrence of Barred Owls have helped inform a baseline, two-species population simulation model of competitive interactions between Northern Spotted Owls and Barred Owls (Perlman, 2017). This initial simulation study explored options for Barred Owl removal and management strategies in different parts of the Pacific Northwest. The newly developed simulation model built upon a spatially explicit, individual-based model for northern Spotted Owls (U.S. Fish and Wildlife Service, 2013). With further development and testing, the simulation model can be used to examine the cost and potential benefits of alternative management strategies for Barred Owls and Spotted Owls at multiple spatial scales.

\section{Summary}

- From 2015 to 2017, pre- and post-treatment occupancy surveys and experimental removal of Barred Owls were completed at three experimental study areas: Cle Elum, Washington (CLE), Oregon Coast Range (COA), and Klamath-Union-Myrtle, Oregon (KLA-UM). Removals of Barred Owls were completed in CLE and COA during September 2015-August 2017, and in KLA-UM during September 2016-August 2017. Removals primarily were done during the nonbreeding season (September-April), but localized removals of non-nesting Barred Owls were completed in Oregon during the breeding season (April-August) in 2017.

- Long-term demographic monitoring of Spotted Owls was continued at 341 territories historically occupied by Spotted Owls in established treatment (Barred Owls removed) and control (no Barred Owls removed) areas in the three experimental study areas.

- In 2017, surveys of Barred Owls at 762 survey sites (500-ha hexagons) detected an average of $1.4(\mathrm{SD}=1.4)$ and $0.8(\mathrm{SD}=0.9)$ pairs of Barred Owls per site in control and treatment areas, respectively. On average, we detected up to 3.3 times as many Barred Owls in COA as compared to the KLA-UM and CLE.

- In 2017, surveys of Spotted Owls detected territorial pairs at a total of 19 (11 percent) of 167 historical territories in control areas, and 20 (11 percent) of 174 historical territories in treated areas. Six (31 percent) of 19 pairs of Spotted Owls successfully fledged at least one young in control areas, whereas 5 ( 25 percent) of 20 pairs produced at least one young in treatment areas.

- We removed a total of 883 Barred Owls from treatment areas during 2015-17 (209 in CLE, 490 in COA, and 184 in KLA-UM).

- We observed a transition in age-class of Barred Owls collected from treatment areas during 2015-17, with a substantial increase in the proportion of subadults collected after established resident adults (birds greater than or equal to 3 years old) were removed. This finding demonstrated that younger, first- and second-year owls were available from surrounding landscapes to quickly fill territory vacancies created by experimental removals.

- In CLE, we estimated that the probability of use by territorial pairs of Barred Owls in treated sites declined by 52 percent between 2015 and 2017, and use was 22 percent lower in treated sites relative to untreated sites. In COA, the probability of use in treated sites declined by 24 percent between 2015 and 2017, and use was 25 percent lower relative to untreated sites. In KLA-UM, the probability of use in treated sites increased by 6 percent after 1 year of removals, and use was 9 percent lower relative to untreated sites. The probability of use by Barred Owls on control areas at KLA-UM increased by about 19 percent between 2016 and 2017. 
- Local extinction (that is, the probability that a site used by a pair of Barred Owls the year prior to removals was not used in the year after removals) were 38 and 15 percent greater in treated areas relative to untreated areas following two seasons of removals in CLE and COA, respectively. Top-models for KLA-UM indicated equivocal effects of removals on local extinction after one season of removals.

- After removals, annual probabilities of a site being recolonized by a territorial pair of Barred Owls were substantially greater in COA and KLA-UM (0.38-0.39) relative to CLE (0.11). Our initial data and results indicated that removals had stronger effects on local extinction rates relative to colonization.

- Pre-treatment estimates of intensity of use (mean number of individual Barred Owls using a 500ha survey site) in treatment areas ranged from $3.4(95 \% \mathrm{CI}=2.6-4.1)$ in KLA-UM to $8.0(95 \%$ $\mathrm{CI}=6.7-9.3)$ in COA. After removals, intensity of use by individuals decreased in treatment areas, but the timing of decrease relative to when removals were initiated varied among study areas (fastest rate of decline observed in CLE).

- Estimates of use by territorial pairs of Barred Owls, and intensity of use by individuals, indicated increases in numbers of Barred Owls during the study period in untreated (control) areas, but only in Oregon. In contrast, we observed a decline in measures of use and intensity of use by Barred Owls in Washington.

- Initial experimental removals of Barred Owls had little measurable effect on occupancy and reproduction of Spotted Owls after the first 1-2 years of implementation. Long-term observations of territory occupancy and reproduction of Spotted Owls illustrated historically low levels in 2017 in all study areas.

- Additional years of study are required to determine the effects of experimental removals of Barred Owls on population trends of Spotted Owls. A detailed BACI analysis of the effects of Barred Owl removals on Spotted Owl site-occupancy dynamics and vital rates (recruitment, survival, rate of population change) is scheduled for January 2019 (see Work and Reporting Schedule below). 


\section{Work and Reporting Schedule}

[BR: Breeding season (April-August); NB: Non-breeding season (September-March)]

\begin{tabular}{|c|c|c|c|c|c|c|c|c|c|c|c|c|}
\hline $\begin{array}{l}\text { Data collection by } \\
\text { study area }\end{array}$ & $\begin{array}{c}\text { BR } \\
2015\end{array}$ & $\begin{array}{c}\text { NB } \\
2015- \\
16 \\
\end{array}$ & $\begin{array}{c}\text { BR } \\
2016\end{array}$ & $\begin{array}{c}\text { NB } \\
2016- \\
17\end{array}$ & $\begin{array}{c}\text { BR } \\
2017\end{array}$ & $\begin{array}{c}\text { NB } \\
2017- \\
18 \\
\end{array}$ & $\begin{array}{c}\text { BR } \\
2018\end{array}$ & $\begin{array}{c}\text { NB } \\
2018- \\
19 \\
\end{array}$ & $\begin{array}{c}\text { BR } \\
2019\end{array}$ & $\begin{array}{c}\text { NB } \\
2019- \\
20 \\
\end{array}$ & $\begin{array}{c}B R \\
2020\end{array}$ & $\begin{array}{c}\text { NB } \\
2020- \\
21\end{array}$ \\
\hline \multicolumn{13}{|l|}{$\begin{array}{l}\text { Cle Elum, } \\
\text { Washington }\end{array}$} \\
\hline \multicolumn{13}{|l|}{$\begin{array}{l}\text { Pre-removal } \\
\text { surveys }\end{array}$} \\
\hline \multicolumn{13}{|l|}{$\begin{array}{l}\text { Removal of } \\
\text { Barred Owls }\end{array}$} \\
\hline \multicolumn{13}{|l|}{$\begin{array}{l}\text { Post-removal } \\
\text { surveys }\end{array}$} \\
\hline \multicolumn{13}{|l|}{$\begin{array}{l}\text { Coast Range, } \\
\text { Oregon }\end{array}$} \\
\hline \multicolumn{13}{|l|}{$\begin{array}{l}\text { Pre-removal } \\
\text { surveys }\end{array}$} \\
\hline \multicolumn{13}{|l|}{$\begin{array}{l}\text { Removal of } \\
\text { Barred Owls }\end{array}$} \\
\hline \multicolumn{13}{|l|}{$\begin{array}{l}\text { Post-removal } \\
\text { surveys }\end{array}$} \\
\hline \multicolumn{13}{|l|}{$\begin{array}{l}\text { Klamath-UM, } \\
\text { Orgon }\end{array}$} \\
\hline \multicolumn{13}{|l|}{$\begin{array}{l}\text { Pre-removal } \\
\text { surveys }\end{array}$} \\
\hline \multicolumn{13}{|l|}{$\begin{array}{l}\text { Removal of } \\
\text { Barred Owls }\end{array}$} \\
\hline \multicolumn{13}{|l|}{$\begin{array}{l}\text { Post-removal } \\
\text { surveys }\end{array}$} \\
\hline \multicolumn{13}{|l|}{$\begin{array}{c}\text { Analysis and } \\
\text { reporting }\end{array}$} \\
\hline $\begin{array}{l}\text { Analysis of } \\
\text { demographic } \\
\text { response of } \\
\text { Spotted Owls to } \\
\text { removals }\end{array}$ & & & & $\begin{array}{l}\text { Hoopa- } \\
\text { NWC }\end{array}$ & & & & $\begin{array}{l}\text { All } \\
\text { study } \\
\text { areas }\end{array}$ & & $\begin{array}{l}\text { All } \\
\text { study } \\
\text { areas }\end{array}$ & & $\begin{array}{l}\text { All } \\
\text { study } \\
\text { areas }\end{array}$ \\
\hline \multicolumn{13}{|l|}{$\begin{array}{l}\text { USGS progress } \\
\text { reports published }\end{array}$} \\
\hline \multicolumn{13}{|l|}{$\begin{array}{l}\text { Conference } \\
\text { presentations }\end{array}$} \\
\hline $\begin{array}{l}\text { Progress updates to } \\
\text { project partners/ } \\
\text { collaborators }\end{array}$ & & & & & & & & & & & & \\
\hline
\end{tabular}




\section{Acknowledgments}

We are indebted to K. Austin, K. Bagnall, J. Butch, M. Campbell, S. Hanson, J. Hazen, M. Hunt, B. Gill, M. Landever, C. Lebow, M. Nickols, T. Plawman, S. Reffler, L. Richardson, J. Rowe, and T. Smith for their field assistance with Barred Owls. C. McCafferty, S. Sovern, A. Woodrow, and R. Horn provided helpful logistical assistance. We also thank R. Crutchley, K. Fukuda, M. Johnston, T.

Kaufmann, N. Kleponis, L. Kufta-Christie, C. Larson, B. Mason, A. Mikkelsen, A. Thomas, K. Wert, A. Price, J. Mowdy, H. Wise, and the many others for their field assistance with Spotted Owls. Robin Bown provided key guidance on study design, federal and state permitting requirements, and landowner access agreements. We thank the many federal, state, and private landowners who provided permission to access their lands and for providing logistical support essential to field activities and data collection. Funding for this research is being provided by the U.S. Fish and Wildlife Service, the Bureau of Land Management, the U.S. Forest Service, and the U.S. Geological Survey. We thank three reviewers for providing helpful comments that improved the quality of this report. The information in this report is preliminary or provisional and is subject to revision, pending final analyses. It is being provided to meet the need for timely best science, and is provided on the condition that neither the USGS nor the U.S. Government shall be held liable for any damages resulting from the authorized or unauthorized use of the information.

\section{References Cited}

Barker, R.J., Schofield, M.R., Link, W.A., and Sauer, J.R., 2017, On the reliability of $N$-mixture models for count data: Biometrics, v. 12734, p. 1-9.

Burnham, K.P., and Anderson, D.R., 2002, Model selection and multimodel inference-A practical information-theoretic approach 2nd ed.: New York, Springer-Verlag, 488 p.

Diller, L.V., Dumbacher, J.P., Bosch, R.P., Bown, R.R., and Gutiérrez, R.J., 2014, Removing Barred Owls from local areas-Techniques and feasibility: Wildlife Society Bulletin, v. 38, no. 1, p. $211-$ 216. https://doi.org/10.1002/wsb.381.

Diller, L.V., Hamm, K.A., Early, D.A., Lamphear, D.W., Dugger, K.M., Yackulic, C.B., Schwarz, C.J., Carlson, P.C., and McDonald, T.L., 2016, Demographic response of northern Spotted Owls to Barred Owl removal: The Journal of Wildlife Management, v. 80, no. 4, p. 691-707. https://doi.org/10.1002/jwmg. 1046.

Dugger, K.M., Forsman, E.D., Franklin, A.B., Davis, R.J., White, G.C., Schwarz, C.J., Burnham, K.P., Nichols, J.D., Hines, J.E., Yackulic, C.B., Doherty, P.F., Jr., Bailey, L., Clark, D.A., Ackers, S.H., Andrews, L.S., Augustine, B., Biswell, B.L., Blakesley, J., Carlson, P.C., Clement, Matthew, J., Diller, L.V., Glenn, E.M., Green, A., Gremel, S.A., Herter, D.R., Higley, J.M., Hobson, J., Horn, R.B., Huyvaert, K.P., McCafferty, C., McDonald, T., McDonnell, K., Olson, G.S., Reid, J.A., Rockweit, J., Ruiz, V., Saenz, J., and Sovern, S.G., 2016, The effects of habitat, climate and Barred Owls on long-term demography of Northern Spotted Owls: The Condor-Ornithological Applications, v. 118, p. 57-116.

Ferrer, M., Penteriani, V., Balbontín, J., and Pandolfi, M., 2003, The proportion of immature breeders as a reliable early warning signal of population decline - Evidence from the Spanish imperial eagle in Doñana: Biological Conservation, v. 114, no. 3, p. 463-466. https://doi.org/10.1016/S00063207(03)00085-5.

Franklin, A.B., Anderson, D.R., Forsman, E.D., Burnham, K.P., and Wagner, F.W., 1996, Methods for collecting and analyzing demographic data on the northern Spotted Owl: Studies in Avian Biology, v. 17 , p. 12-20. 
Franklin, A.B., Carlson, P.C., and Rockweit, J.T., 2016, Monitoring Barred Owls on the WCSA northern Spotted Owl demographic area-2016 progress report: Report to the U.S. Geological Survey, U.S. Department of Interior Interagency Agreement G15PG00030.

Gabriel, M.W., Diller, L.V., Dumbacher, J.P., Wengert, G.M., Higley, J.M., Poppenga, R.H., and Mendia, S., 2018, Exposure to rodenticides in Northern Spotted and Barred Owls on remote forest lands in northwestern California-Evidence of food web contamination: Avian Conservation and Ecology, v. 13, no. 2, 9 p., https://doi.org/10.5751/ACE-01134-130102.

Higley, J.M., 2017, Barred Owl experimental removal: Hoopa study area report to National Fish and Wildlife Foundation, $23 \mathrm{p}$.

Holm, S.R., Noon, B.R., Wiens, J.D., and Ripple, W.J., 2016, Potential trophic cascades triggered by the Barred Owl range expansion: Wildlife Society Bulletin, v. 40, no. 4, p. 615-624. https://doi.org/10.1002/wsb.714.

Johnson, D.H., White, G.C., Franklin, A.B., Diller, L.V., Blackburn, I., Pierce, D.J., Olson, G.S., Buchanan, J.B., Thrailkill, J., Woodbridge, B., and Ostwald, M., 2008, Study designs for Barred Owl removal experiments to evaluate potential effects on northern Spotted Owls: Olympia, Washington Department of Fish and Wildlife.

Lesmeister, D., Horn, R., Crutchley, R., Fukuda, K., Kaufmann, T., Larson, C., Price, A., and Wise, H., 2018, Demographic characteristics of northern Spotted Owls (Strix occidentalis caurina) in the Klamath Mountain Province of Oregon, 1990-2017-Annual research report, USDI Bureau and Land Management, Roseburg, Oregon; and USDA Forest Service: Corvallis, Oregon, Pacific Northwest Research Station, 21 p., https://www.fs.fed.us/r6/reo/monitoring/reports/

Lesmeister, D., McCafferty, C., Johnston, M., Kleponis, N., Kufta-Christie, L., Mason, C., Thomas, A., and Wert, K., 2018, Demographic characteristics of Spotted Owls in the Oregon Coast Range, 19902017: Annual research report. USDA Forest Service, Pacific Northwest Research Station; and Department of Fisheries and Wildlife, Oregon State University, Corvallis, Oregon, 25 p., https://www.fs.fed.us/r6/reo/ monitoring/reports/.

Lesmeister, D., Sovern, S., and Mikkelsen, A., 2018, Demography of Spotted Owls on the east slope of the Cascade Range, Washington, 1989-2017: Annual research report. USDA Forest Service, Pacific Northwest Research Station; and Department of Fisheries and Wildlife, Oregon State University, Corvallis, OR. 26 p. https://www.fs.fed.us/r6/reo/monitoring/reports/.

Lint, J.B., Noon, B.R., Anthony, R.G., Forsman, E.D., Raphael, M.G., Collopy, M., and Starkey, E., 1999, Northern Spotted Owl effectiveness monitoring plan for the northwest forest plan: U.S. Forest Service, General Technical Report PNW-GTR-440.

MacKenzie, D.I., Nichols, J.D., Lachman, G.B., Droege, S., Royle, J.A., and Langtimm, C.A., 2002, Estimating site occupancy rates when detection probabilities are less than one: Ecology, v. 83, no. 8, p. 2248-2255, https://doi.org/10.1890/0012-9658(2002)083[2248:ESORWD]2.0.CO;2.

MacKenzie, D.I., Nichols, J.D., Royle, J.A., Pollack, K.H., Bailey, L.L., and Hines, J.E., 2006, Occupancy estimation and modeling-Inferring patterns and dynamics of species occurrence: Burlington, Massachusetts, Academic Press.

Nichols, J.D., Thomas, L., and Conn, P.B., 2009, Inferences about landbird abundance from count data-Recent advances and future directions, in Thomson, D.L., Cooch, E.G., and Conroy, M.J., eds., Modeling Demographic Processes in Marked Populations: New York, New York, USA, Springer, p. 201-235, https://doi.org/10.1007/978-0-387-78151-8_9.

Penteriani, V., Ferrer, M., and Delgado, M.D.M., 2011, Floater strategies and dynamics in birds, and their importance in conservation biology-Towards an understanding of nonbreeders in avian populations: Animal Conservation, v. 14, no. 3, p. 233-241. https://doi.org/10.1111/j.14691795.2010.00433.x. 
Perlman, K.R., 2017, Using a two-species individual-based model to examine the population responses of northern Spotted Owls to experimental removal of Barred Owls in the Pacific Northwest. Thesis, Oregon State University, Corvallis, Oregon, USA, p. 1-99.

Royle, J.A., 2004, N-mixture models for estimating population size from spatially replicated counts: Biometrics, v. 60, no. 1, p. 108-115. https://doi.org/10.1111/j.0006-341X.2004.00142.x

U.S. Fish and Wildlife Service, 2013, Experimental removal of Barred Owl to benefit threatened northern Spotted Owls: Final Environmental Impact Statement, U.S. Department of Interior, Portland, Oregon, USA.

Weidensaul, C.S., Colvin, B.A., Brinker, D.R., and Huy, J.S., 2011, Use of ultraviolet light as an aid in age classification of owls: The Wilson Journal of Ornithology, v. 123, no. 2, p. 373-377. https://doi.org/10.1676/09-125.1.

White, G.C., and Burnham, K.P., 1999, Program MARK-Survival estimation from populations of marked animals: Bird Study, v. 46, sup1, p. S120-S138, https://doi.org/10.1080/00063659909477239.

Wiens, J.D., Anthony, R.G., and Forsman, E.D., 2011, Barred Owl occupancy surveys within the range of the northern Spotted Owl: The Journal of Wildlife Management, v. 75, no. 3, p. 531-538. https://doi.org/10.1002/jwmg.82.

Wiens, J.D., Anthony, R.G., and Forsman, E.D., 2014, Competitive interactions and resource partitioning between northern Spotted Owls and Barred Owls in western Oregon: Wildlife Monographs, v. 185, no. 1, p. 1-50. https://doi.org/10.1002/wmon.1009.

Wiens, J.D., Dugger, K.M., Lewicki, K.E., and Simon, D.C., 2017, Effects of experimental removal of Barred Owls on population demography of northern Spotted Owls in Washington and Oregon-2016 progress report: U.S. Geological Survey Open-File Report 2017-1040, 23 p., https://doi.org/10.3133/ofr20171040.

Yackulic, C.B., Reid, J., Nichols, J.D., Hines, J.E., Davis, R., and Forsman, E., 2014, The roles of competition and habitat in the dynamics of populations and species distributions: Ecology, v. 95, no. 2, p. 265-279. https://doi.org/10.1890/13-0012.1. 


\section{Appendix 1. Ranking of Multi-Season Occupancy Models Used to Characterize Variation in the Probabilities of Use, Extinction, Colonization, and Detection of Territorial Pairs of Barred Owls on Three Experimental Study Areas in Washington and Oregon, 2015-17.}

We show model parameter structure and the estimated direction of treatment effects for competitive models $\left(\leq 2 \mathrm{AIC}_{c}\right)$ for each study area. Model parameters defined as: $\widehat{\psi}_{1}=$ probability of use in the first year of study (initial occupancy), $\widehat{\varepsilon}=$ the probability that a previously used site was not used in the subsequent year (extinction), $\hat{\gamma}=$ the probability that a previously vacant site was colonized in the subsequent year (colonization) and $\hat{p}=$ the probability of detection. Models with treatment (trt) effects allow parameter estimates to vary between treatment (removal) and control areas. Time effects on detection modeled as constant (.), varying between treatment and control areas in years following removals (trtBA), varying with survey period (survey), or year. $\mathrm{AIC}_{c}=$ Akaike's Information Criterion for small sample size, $\Delta \mathrm{AIC}_{c}=$ difference between the $\mathrm{AIC}_{c}$ value of each model and the lowest $\mathrm{AIC}_{c}$ model, $K=$ the number of model parameters, and Deviance is defined as the difference in $-2\left[\log _{\mathrm{e}}(\right.$ Likelihood $\left.)\right]$ of the current model and $-2\left[\log _{\mathrm{e}}(\right.$ Likelihood $\left.)\right]$ of the saturated model.

\begin{tabular}{|c|c|c|c|c|c|c|c|c|c|}
\hline Study area & Model & $\widehat{\Psi}_{1}$ & $\widehat{\widehat{\varepsilon}}$ & $\hat{\gamma}$ & $\widehat{p}$ & $\Delta \mathrm{AIC}_{c}$ & $\mathbf{w}_{i}$ & $K$ & Deviance \\
\hline \multirow{4}{*}{$\begin{array}{l}\text { Cle Elum, } \\
\text { Washington }\end{array}$} & & & & & & & & & \\
\hline & 1 & $\operatorname{trt}(+)$ & $\operatorname{trt}(+)$ & . & yr, survey, trtBA (-) & 0.0 & 0.46 & 11 & 1351.43 \\
\hline & 2 & $\operatorname{trt}(+)$ & $\operatorname{trt}(+)$ & $\operatorname{trt}(+)$ & yr, survey, trtBA (-) & 1.4 & 0.23 & 12 & 1350.72 \\
\hline & 3 & $\operatorname{trt}(+)$ & $\operatorname{trt}(+)$ & $\mathrm{yr}$ & yr, survey, trtBA (-) & 2.0 & 0.17 & 12 & 1351.36 \\
\hline \multirow{4}{*}{$\begin{array}{l}\text { Coast Range, } \\
\text { Oregon }\end{array}$} & & & & & & & & & \\
\hline & 1 & . & $\mathrm{yr}, \operatorname{trt}(+)$ & . & $\mathrm{yr}$, survey, trtBA (-) & 0.0 & 0.48 & 11 & 2267.89 \\
\hline & 2 & . & $\mathrm{yr}, \operatorname{trt}(+)$ & $\mathrm{yr}$ & yr, survey, trtBA (-) & 1.8 & 0.19 & 12 & 2276.64 \\
\hline & 3 & . & $\mathrm{yr}, \operatorname{trt}(+)$ & $\operatorname{trt}(-)$ & yr, survey, trtBA (-) & 2.0 & 0.17 & 12 & 2276.86 \\
\hline \multirow[t]{6}{*}{$\begin{array}{l}\text { Klamath-UM, } \\
\text { Washington }\end{array}$} & 1 & . & . & . & survey & 0.0 & 0.25 & 6 & 1335.79 \\
\hline & 2 & . & . & $\operatorname{trt}(+)$ & survey & 0.6 & 0.18 & 7 & 1334.32 \\
\hline & 3 & . & $\operatorname{trt}(+)$ & $\operatorname{trt}(+)$ & survey & 1.2 & 0.13 & 8 & 1332.91 \\
\hline & 4 & . & $\operatorname{trt}(+)$ & $\operatorname{trt}(+)$ & yr, survey & 1.5 & 0.12 & 9 & 1331.12 \\
\hline & 5 & $\operatorname{trt}(-)$ & $\operatorname{trt}(-)$ & $\operatorname{trt}(+)$ & survey & 1.5 & 0.12 & 9 & 1331.13 \\
\hline & 6 & $\operatorname{trt}(-)$ & $\operatorname{trt}(-)$ & $\operatorname{trt}(+)$ & yr, survey & 1.8 & 0.1 & 10 & 1329.31 \\
\hline
\end{tabular}




\section{Appendix 2. Ranking of Single-Season $\mathrm{N}$-mixture Models Used to Characterize Variation in Intensity of Use, and Detection of Individual Barred Owls on Three Experimental Study Areas in Washington and Oregon, 2015-17}

Model parameters defined as: $\lambda=$ intensity of use (the average number of individual Barred Owls with home ranges overlapping with the focal survey plot; Nichols and others, 2009), and $r_{i}$, = unconditional probability of detecting an individual Barred Owl at sampling unit $i$ during the breeding season (Royle, 2004). Covariate effects allow estimates to vary by treatment level (control compared with treatment; trt) or by experimental study area (area). Time effects modeled as constant (.), varying with survey period (survey), or year. $\mathrm{AIC}_{c}=$ Akaike's Information Criterion for small sample size, $\Delta \mathrm{AIC}_{c}=$ difference between the $\mathrm{AIC}_{c}$ value of each model and the lowest $\mathrm{AIC}_{c}$ model, $K=$ the number of model parameters, and Deviance is defined as the difference in $-2\left[\log _{\mathrm{e}}\right.$ (Likelihood)] of the current model and $-2\left[\log _{\mathrm{e}}(\right.$ Likelihood $\left.)\right]$ of the saturated model.

\begin{tabular}{|c|c|c|c|c|c|}
\hline Model & $\mathrm{AlC}_{c}$ & $\Delta \mathrm{AIC}_{c}$ & $\mathbf{w}_{i}$ & K & Deviance \\
\hline$\lambda\left(\right.$ area* $\left.{ }^{*} * \operatorname{trt}\right) r(\operatorname{trtBA})$ & 13313.6 & 0.0 & 0.3 & 19 & 13275.3 \\
\hline$\lambda\left(\right.$ area* $\left.\mathrm{yr}^{*} \operatorname{trt}\right) r(\operatorname{trt})$ & 13314.2 & 0.6 & 0.2 & 18 & 13277.9 \\
\hline$\lambda\left(\right.$ area* $\left.\left.{ }^{*} * \operatorname{trt}\right) r(\mathrm{yr} * \operatorname{trt})\right)$ & 13315.4 & 1.7 & 0.1 & 22 & 13270.9 \\
\hline$\lambda(\operatorname{area} * \mathrm{yr} * \operatorname{trt}) r(\mathrm{yr}+\operatorname{trtBA})$ & 13315.5 & 1.9 & 0.1 & 20 & 13275.1 \\
\hline$\lambda\left(\right.$ area* $\left.{ }^{*} * \operatorname{trt}\right) r(\mathrm{yr}+\mathrm{trt})$ & 13315.6 & 1.9 & 0.1 & 20 & 13275.1 \\
\hline$\lambda($ area*yr*trt) $r()$. & 13316.5 & 2.9 & 0.1 & 17 & 13282.2 \\
\hline$\lambda($ area*yr*trt $) r(\mathrm{yr})$ & 13316.6 & 3.0 & 0.1 & 19 & 13278.2 \\
\hline$\lambda(\operatorname{area} * \mathrm{yr} * \operatorname{trtBA}) r(\operatorname{trtBA})$ & 13334.4 & 20.8 & 0.0 & 16 & 13302.1 \\
\hline$\lambda\left(\right.$ area $\left.^{*} \mathrm{yr}\right) r(\operatorname{trtBA})$ & 13342.9 & 29.2 & 0.0 & 11 & 13320.8 \\
\hline$\lambda($ area $+\mathrm{yr}+\operatorname{trt}) r(\operatorname{trtBA})$ & 13395.7 & 82.1 & 0.0 & 11 & 13373.6 \\
\hline$\lambda($ area $+\mathrm{yr}) r(\operatorname{trtBA})$ & 13414.4 & 100.8 & 0.0 & 9 & 13396.3 \\
\hline$\lambda($ area $+\operatorname{trt}) r(\operatorname{trtBA})$ & 13428.4 & 114.8 & 0.0 & 7 & 13414.4 \\
\hline$\lambda($ area $) r(\operatorname{trtBA})$ & 13446.5 & 132.8 & 0.0 & 6 & 13434.4 \\
\hline$\lambda(\operatorname{trt}) r(\operatorname{trtBA})$ & 14039.5 & 725.9 & 0.0 & 5 & 14029.5 \\
\hline$\lambda() r.(\operatorname{trtBA})$ & 14040.6 & 726.9 & 0.0 & 4 & 14032.6 \\
\hline
\end{tabular}



Publishing support provided by the U.S. Geological Survey Science Publishing Network, Tacoma Publishing Service Center

For more information concerning the research in this report, contact the Director, Forest and Rangeland Ecosystem Science Center U.S. Geological Survey

777 NW 9th St., Suite 400

Corvallis, Oregon 97330

https://fresc.usgs.gov/ 
届

త్

웅

궁

은

ż 